\title{
Determinants of poor glycemic control among adult patients with type 2 diabetes mellitus in Jimma University Medical Center, Jimma zone, south west Ethiopia: a case control study
}

Yitagesu Mamo ${ }^{*}$, Fekede Bekele ${ }^{2}$, Tadesse Nigussie $^{3}$ and Ameha Zewudie ${ }^{4}$

\begin{abstract}
Objective and background: In 2015 approximately 5.0 million people were estimated to have died from diabetes. Poor glycemic control is the most determinant of diabetes-related complication and death. The percentage of patients whose blood glucose level are not well controlled remains high yet. The aim of this study is to identify the determinants of poor glycemic control at the diabetes clinic of the Jimma University Medical Center from April 01 to June 30/2017.

Methods: Facility-based case-control study design was conducted on patients with type 2 diabetes mellitus on follow-up at the diabetes clinic of Jimma University medical center. The consecutive sampling technique was employed and data were collected from April to June 2017. The data were entered using Epidata manager version 4.0.2 and exported to SPSS Version 21 for analysis. Logistic regression analysis was performed and variables with the $p$-value of less than 0.05 were considered as statistically significant determinants of poor glycemic control.

Result: The study was conducted on 410 patients, of which 228 males and 182 females. The determinants of poor glycemic control were comorbidities [Adjusted odd ratio(AOR) $=2.56,95 \% \mathrm{Cl}=1.10-5.96$ ], lack of self-monitoring blood glucose $[A O R=3.44,95 \% \mathrm{Cl}=1.33-8.94]$, total cholesterol level of $200 \mathrm{mg} / \mathrm{dl}$ or more $[\mathrm{AOR}=3.62,95 \% \mathrm{Cl}=1.46-8.97]$, diabetes duration of greater than 7 years $[A O R=3.08,95 \% \mathrm{Cl}=1.33-7.16]$, physical activity of three or less than three days $[A O R=4.79,95 \% \mathrm{Cl}=1.70-13.53]$, waist to hip ratio of 0.9 or greater for male and 0.85 or greater for female $[A O R=3.52,95 \% \mathrm{Cl}=1.23-10.11]$, being on metformin plus insulin $[A O R=9.22,95 \% \mathrm{Cl}=2.90-29.35]$ and being on insulin $[A O R=4.48,95 \% \mathrm{Cl}=1.52-13.16]$.

Conclusion: Lack of Self-monitoring blood glucose, presence of comorbidities, duration of diabetes mellitus, physical activity of three or less than three days, total cholesterol of $200 \mathrm{mg} / \mathrm{dl}$ or more, waist to hip ratio of 0.9 or greater for male and 0.85 or greater for female, and types of antidiabetic medication were the independent predictors of poor glycemic control. Effort should be made towards reducing these factors by the concerned body.
\end{abstract}

Keywords: Determinants, Diabetes mellitus, Glycemic control, Jimma university medical center

\footnotetext{
* Correspondence: mamoyitagesu@gmail.com

'Department of Pharmacy, College of medicine and health science, Mizan

Tepi University, Mizan Teferi, Ethiopia

Full list of author information is available at the end of the article
}

(C) The Author(s). 2019 Open Access This article is distributed under the terms of the Creative Commons Attribution 4.0 International License (http://creativecommons.org/licenses/by/4.0/), which permits unrestricted use, distribution, and reproduction in any medium, provided you give appropriate credit to the original author(s) and the source, provide a link to the Creative Commons license, and indicate if changes were made. The Creative Commons Public Domain Dedication waiver (http://creativecommons.org/publicdomain/zero/1.0/) applies to the data made available in this article, unless otherwise stated. 


\section{Background}

Diabetes is among the largest and rapidly growing global health emergencies of the twenty-first century. Worldwide about 415 million adults are living with diabetes and it is projected to be 642 million in 2040 [1].

A major concern in the management of diabetes is the occurrence of complications. Complications in diabetes are related to the damaging effects of hyperglycemia. The major long-term diabetes complications are macrovascular (peripheral arterial disease, stroke, and coronary artery disease); and microvascular (retinopathy, neuropathy, and nephropathy [2]. Clinical trials have demonstrated that tight blood glucose control correlates with a reduction in those complications in a patient with type 2 diabetes mellitus (T2DM) [3, 4]. Another study also revealed that intensive glucose control reduced risk for some cardiovascular disease like; nonfatal myocardial infarction in T2DM but did not reduce risk for cardiovascular or all-cause mortality [5].

Diabetes mellitus created a great health and economic burden because of the direct costs of treatment, manhours lost due to the debilitating effect the disease on the individual and society at large in the world $[6,7]$. In 2015, approximately 5.0 million people were estimated to have died from diabetes [8]. In many urban areas of Sub-Saharan Africa, diabetes is as higher as or higher than, those in most Western European countries [9, 10].A study shows that $5 \%$ of adult deaths in Addis Ababa, Ethiopia were attributed to diabetes [11].

Glycemic control is the common factor that determines death and complication from diabetes [12, 13]. The risk of complication in type $2 \mathrm{DM}$ is directly related to prior glucose control level. A study revealed that in patients with type 2 diabetes, $\mathrm{HbA}(1 \mathrm{c})$ levels were associated with lower risks of macrovascular events and death down to a cutpoint of $7.0 \%$ while microvascular events down to a cutpoint of $6.5 \%$ [14].

As many factors affect blood glucose level, reasons for poor glycemic control is multifactorial and complex.. Factors like; a delay in the beginning and intensification of insulin unnecessarily, poor adherence to treatment, diet and exercise affect glycemic control [15].

In addition to these, another study shows that in patients with type 2 diabetes short disease duration and treatment with few oral glucose-lowering drugs were predictors of blood glucose level. Moreover, it also indicated that in developing nations; patients, doctors and health service factors, all affect glycemic targets [16]. Yet, another study revealed age and length of time patient lived with DM, receiving monotherapy compared with the combination of insulin and oral antidiabetics were more likely associated with good glycemic control, and self-management behavior did not appear to influence glycemic control [17].
In Ethiopia, a number of studies were conducted on factors affecting glycemic control, in different hospital of the country. Two of them indicated that younger age, hypertension, and non-adherence to diabetes self-management behaviors were independent predictors of poor glycemic control $[18,19]$. In similar ways, a cross-sectional study done in Jimma University Medical center (JUMC) indicated that patients who have no formal education and farmer, taking a combination of insulin and oral medication, and poor adherence to the medication associated with poor glycemic control [20].

However, changeable cardiovascular risk factors such as dyslipidemia, obesity, physical inactivity, smoking were not studied well in patients with diabetes in Ethiopia. A little has been done on dyslipidemia from cardiovascular risk factor as a factor contributing to glycemic control in Addis Ababa [19], and only hypertension from adjustable cardiovascular risk factor was investigated as a factor contributing to glycemic control in JUMC [20]. The studies previously conducted in Ethiopia were cross-sectional [18, 20, 21]. This study was a case-control; besides the modifiable cardiovascular risk factors associated with glycemic control was also investigated.

\section{Objectives of the study}

- To identify the predictors of poor glycemic control among adult patients with type 2 diabetes mellitus on follow up at the diabetic clinic of JUMC, 2017.

\section{Methods}

\section{Study setting and period}

This study was conducted from April 01 to June 30, 2017, at the diabetic clinic of JUMC. Geographically, it is located in Jimma city, $352 \mathrm{~km}$ southwest of Addis Ababa, the capital city of Ethiopia. JUMC is the only teaching hospital in southwest Ethiopia, providing services for approximately 15,000 inpatients, 160,000 outpatient attendants, 11,000 emergency cases and 4500 deliveries annually with the catchment population of about 15 million people [http:// www.ju.edu.et/jimma-universityspecialized hospital-jush].

\section{Study design and population}

Facility based-case control study was conducted. The source population was all type 2 diabetes mellitus. The study population was all patients with type 2 diabetes mellitus who presented at a diabetic clinic during the data collection period and those who fulfilled the eligibility criteria. Cases were patients with type 2 diabetes mellitus who had poor glycemic control and Controls were patients with type 2 diabetes mellitus who had good glycemic control. 


\section{Inclusion criteria}

Patients with type 2 diabetes mellitus whose age were greater than 18 years and who had at least three months consecutive follow up were included in both cases and control.

\section{Exclusion criteria}

In both cases and controls, patients with type 2 diabetes mellitus who were mentally unstable or critically ill and who were not able to respond were excluded.

\section{Sample size and sampling technique Sample size}

Epi info version 7 was used to calculate sample size by two population proportions with the assumption of $95 \%$ Confidence Interval (CI), 80\% power, and 1:1 case to controls ratio. Odds Ratio (OR) and proportion of different predictor variable of glycemic control among controls were taken from a study done at Mekelle, Ambo, and Jimma [18, 20, 21]. Then the largest total sample size became 410. Since the ratio of case to control was 1 : 1, the sample size was calculated to be 205 for both cases and controls.

\section{Sampling technique}

All patients with type 2 diabetes mellitus attending the diabetic clinic during the working time of the clinic and eligible were enrolled. Consecutive sampling technique was applied to recruite the required sample sizes of both groups (cases or controls) were achieved. Study participants were interviewed up on their exit from diabetic clinic.

\section{Data collection procedures and instruments}

Data were collected using a structured questionnaire which was developed based on different literatures $[18,20-24]$. The questionnaire was translated from English to Afan Oromo and Amharic and back-translated to English. Checklist was used to collect data related to patients' medications and laboratory parameters.

\section{Data collection process and management}

Information related to socio-demographic characteristics, self-care activities and medication adherence were collected through interviews with the patients. Weight, height, Hip Circumference (HC) and Waist Circumference(WC) were measured during the day of the interview. Three consecutive months Fasting Blood Glucose (FBG), latest Fasting Lipid Profile (FLP) laboratory values within one year and other clinical characteristics were obtained from patients' records.

\section{Study variables}

Dependent variable was the status of glycemic control. Independent variables include socio-demographic variables (age, sex, marital status, religion, educational status, income and occupation), diabetes self-care factors (Self-Monitoring Blood Glucose (SMBG), adherence to antidiabetic medication, knowledge of target blood sugar, attendance diabetic education program, alcohol consumption, khat chewing, adherence to healthy eating plan and cigarette smoking), clinical related factors (duration of diabetes, comorbidities, Waist to Hip Ratio(WHR), Body Mass Index(BMI) and FLP) and medication-related factors(types of antidiabetic medication and polypharmacy).

\section{Operational definitions and measurements}

Glycemic control: patients were categorized based on the American Diabetic Association (ADA) 2017 guideline recommendation [25] into two groups:

Good glycemic control: average fasting blood glucose of $80-130 \mathrm{mg} / \mathrm{dL}$.

Poor glycemic control: average fasting blood glucose of $>130 \mathrm{mg} / \mathrm{dL}$.

Knowledge of target blood glucose: was assessed by use of "yes/no" questions. Mentioning correct answer was coded as " 1 " and failure to mention as " 0 " Then the score was converted to a percentage score. The mean score was used to classify patients into adequate and inadequate knowledge level.

Adherence to diet: If the respondents follow a recommended diet for more than 3 days in last seven days.

Adherence to exercise: If the respondents follow the recommended level of exercise for more than 3 days in the last seven days.

Fasting blood sugar: blood glucose measured from venous blood after at least $8 \mathrm{~h}$ of overnight fasting.

Adherence to medication: if the patients took all his/ her antidiabetic medication in the last seven days.

Alcohol consumption- if reported consumption of alcohol twelve-month prior to the survey.

Polypharmacy: taking more than four medications daily. Simultaneous polypharmacy: was used to estimate the number of drugs a patient is receiving at any given point in time [26].

BMI of $25.0-29.9 \mathrm{~kg} / \mathrm{m} 2$-were classified as overweight and BMI of $\geq 30.0 \mathrm{~kg} / \mathrm{m} 2$ - were classified as obese [27]. Abdominal obesity- Waist to Hip Ratio (WHR) $\geq$ 0.90 for males and $\geq 0.85$ for females [28].

\section{Measurements}

After the participants stood with arms at the sides, feet positioned close together, and weight evenly distributed across the feet, the WC was measured to the nearest $1 \mathrm{~cm}$ three times at the approximate midpoint 
between the lower margin of the last palpable rib and the top of the iliac crest, at the end of a normal exhalation. The mean of the three measurements was calculated and taken at the end. Participants told to relax and take a few deep, natural breaths before the actual measurement was made in order to minimize the inward pull of the abdominal contents during the waist measurement. Participants have already fasted overnight to measure their FBG. This condition was also beneficial for measuring WC. HC of the patients was measured three times to the nearest centimeter at the largest circumference of the buttocks. Both hip and waist circumference were measured with a stretch-resistant tape that is wrapped snugly around the participants and the tape was kept level and parallel to the floor at the point of measurement. This protocol of measurement was per WHO STEPwise approach to surveillance [29]. Height was measured to the nearest centimeter with respondents standing on a hard surface against a wall, using a square and tape measure to the wall. All measurements were recorded to the nearest centimeter. Weight was measured to the nearest $100 \mathrm{~g}$ using a calibrated instrument. WHR was calculated as WC $(\mathrm{cm})$ divided by $\mathrm{HC}(\mathrm{cm})$. BMI was calculated as the weight divided by height squared $(\mathrm{kg} / \mathrm{m} 2)$.

\section{Data processing and analysis}

The data on the questionnaire was entered into Epidata manager version 4.0.2 and double entry verification was made and exported to SPSS version 21 statistical packages for analysis. The data were explored to check outliers, missing data and assumptions. During analysis frequencies of the different variables were determined as necessary; Cross-tabulations and bivariate analysis were performed to select variables for multivariate analysis. Hence variables with a $p$-value $<0.25$ in the bivariate analysis were taken as candidates for multivariable analysis. Finally, multivariable logistic regression analysis was performed to control for the possible confounding effect of the selected variables and variables with a $p$-value of less than 0.05 were taken as statistically significant predictors for poor glycemic control and OR with its $95 \%$ CI was used to show the degree of association between the independent and the outcome variable.

\section{Data quality assurance}

The structured questionnaire was adapted from different related studies. Then it was translated from English to Afan Oromo and Amharic and back-translated into English by the independent person to assure its consistency. Three days training was given for three pharmacists (Bpharm) and 2 nurses (Bsc. Nurse) prior to data collection. The pharmacists collected the data through patient interview and from the card, whereas nurses measured the waist circumference, hip circumference, height and weight of the respondents. A panel of experts (clinical pharmacists) assessed whether the data collection form would measure what it intended to measure and if it was comprehensive enough to collect all the information needed to address the purpose and goals of the study. Then pilot test was done on 21 patients $(5 \%)$ and necessary changes were made based on expert opinion.

\section{Result \\ General characteristics of the study participants}

This study was conducted on 410 patients of type 2 diabetes mellitus, 205 cases, and 205 controls, of which 54 and $58 \%$ were males respectively. The mean \pm SD age of the respondents were $52.63 \pm 10.46$ and $53.33 \pm 11.73 \%$ of cases and controls respectively. More than one-third of both cases and controls were in the age group " $45-54$ years". Seventy four percent of cases and $85 \%$ of control were married. Thirty four percent and $20.5 \%$ of cases and controls, respectively, had no formal education (Table 1).

\section{Diabetes self-care activities}

Forty seven (22.90\%) of cases and 65(31.70\%) of controls had adequate healthy eating plan during the previous week before the study. Twenty two percent of the cases and $45 \%$ of the controls have involved in, at least $30 \mathrm{~min}$ of, physical activity for more than 3 days during the last seven days preceding the study (Table 2).

\section{Types of antidiabetic therapy and polypharmacy}

Thirty six percent of cases were prescribed with Metformin plus Glibenclamide followed by insulin alone (31.70\%). In controls, $31.20 \%$ were prescribed with insulin alone followed by metformin alone $(29.80 \%)$ (Table 3$)$. Twenty four percent (23.90\%) of cases and $10.20 \%$ of control were taking more than or equal to five medications including medication for blood glucose control (Table 3).

\section{Selected clinical characteristics}

The duration of diabetes was greater than 7 years in $52.20 \%$ of the cases and $31.20 \%$ of the controls. Ninty percent $(90.20 \%)$ of the cases and $68.8 \%$ of the controls had WHR of $\geq 0.9$ for males or $\geq 0.85$ for females. From a total of 157 (77 cases and 80 controls) participants for whom laboratory fasting lipid profile of total cholesterol were recorded. The mean total cholestrol was $193+/-11$ in cases and $171+/-14$ in controls. Forty two percent $(41.60 \%)$ of the cases as compared to $18.80 \%$ of the control had total cholesterol level of $\geq 200 \mathrm{mg} / \mathrm{dl}$ (Table 3 ). 
Table 1 Socio-demographic characteristics of adult patients with type 2 diabetes mellitus on follow up at the diabetic clinic of Jimma University medical center, south-west Ethiopia, April 01-June 30, 2017

\begin{tabular}{|c|c|c|c|c|c|c|c|}
\hline Variables & Cases N (\%) & Control N (\%) & Total N (\%) & Variables & Cases N (\%) & Control N (\%) & Total N (\%) \\
\hline Age category & & & & $1500-600$ & $55(26.80)$ & $63(30.70)$ & $118(28.80)$ \\
\hline $25-34$ & $8(3.90)$ & $9(4.40)$ & $17(4.10)$ & $\geq 6000$ & $7(3.40)$ & $5(2.40)$ & $12(2.90)$ \\
\hline $35-44$ & $36(17.60)$ & 35 (17.10) & $71(17.30)$ & No constant income & 39 (19.00) & $23(11.20)$ & $62(15.10)$ \\
\hline $45-54$ & $75(36.60)$ & $69(33.70)$ & $144(35.10)$ & \multirow{3}{*}{\multicolumn{4}{|c|}{$\begin{array}{l}\text { a Catholic and wake data, kambata, }{ }^{\mathrm{b}} \text { walayita, Tigre and Silte, }{ }^{\mathrm{c}} \text { Has not } \\
\text { employed, retired and daily labor }\end{array}$}} \\
\hline $55-64$ & $57(27.80)$ & $60(29.30)$ & $117(28.50)$ & & & & \\
\hline 65 and above & $29(14.10)$ & $32(15.60)$ & $61(14.90)$ & & & & \\
\hline \multicolumn{8}{|l|}{ Gender } \\
\hline Male & $110(53.70)$ & $118(57.60)$ & $228(55.60)$ & & & & \\
\hline Female & $95(46.30)$ & $87(42.40)$ & $182(44.40)$ & \multirow{4}{*}{\multicolumn{4}{|c|}{$\begin{array}{l}\text { Table } 2 \text { Diabetes self-care activities of adult patients with type } \\
2 \text { diabetes mellitus on follow up in a diabetic clinic of Jimma } \\
\text { University medical center, south-west Ethiopia, April 01-June 30, } \\
2017\end{array}$}} \\
\hline Religion & & & & & & & \\
\hline Muslim & $124(60.50)$ & $116(56.60)$ & $240(58.50)$ & & & & \\
\hline Orthodox & $59(28.80)$ & $67(32.70)$ & $126(30.70)$ & & & & \\
\hline Protestant & $20(9.80)$ & $17(8.30)$ & $37(9.00)$ & Variables & Cases, N (\%) & Control, N (\%) & Total N (\%) \\
\hline others $^{a}$ & $2(0.97)$ & $5(2.40)$ & $7(1.70)$ & \multicolumn{4}{|l|}{ Know optimum blood sugar } \\
\hline Ethnicity & & & & No & $123(60.00)$ & $129(62.90)$ & $252(61.50)$ \\
\hline Oromo & $119(58.00)$ & $120(58.50)$ & $239(58.30)$ & Yes & $82(40.00)$ & $76(37.10)$ & $158(38.50)$ \\
\hline Amara & $40(19.50)$ & $34(16.60)$ & $74(18.00)$ & \multicolumn{4}{|l|}{ Diabetes education } \\
\hline Kaficho & $8(3.90)$ & $10(4.90)$ & $18(4.40)$ & Yes & $139(67.80)$ & $143(69.80)$ & $282(68.80)$ \\
\hline Dwuro & $6(2.90)$ & $7(3.40)$ & $13(3.20)$ & No & $66(32.20)$ & $62(30.20)$ & $128(31.20)$ \\
\hline Yem & $14(6.80)$ & $16(7.80)$ & $30(7.30)$ & \multicolumn{4}{|l|}{ Physical activity } \\
\hline Gurage & $12(5.90)$ & $4(2.00)$ & $16(3.90)$ & > 3 days(adequate) & $44(21.50)$ & $92(44.90)$ & $136(33.20)$ \\
\hline Others $^{b}$ & $6(2.90)$ & $14(6.80)$ & $20(4.90)$ & $0-3$ days (in adequate) & $161(78.50)$ & $113(55.10)$ & $274(66.80)$ \\
\hline Marital status & & & & \multicolumn{4}{|c|}{ Self-monitoring blood glucose } \\
\hline Married & $151(73.70)$ & $173(84.40)$ & $324(79.00)$ & Yes & $41(20.00)$ & $61(29.80)$ & $102(24.90)$ \\
\hline Single/divorced /widowed & $54(26.30)$ & $32(15.60)$ & $86(21.00)$ & No & $164(80.00)$ & $144(70.20)$ & $308(75.10)$ \\
\hline Place of residence & & & & \multicolumn{4}{|l|}{ Smoke cigarette } \\
\hline Rural & $122(59.50)$ & $73(35.60)$ & $195(47.60)$ & Yes, now & $3(1.50)$ & $0(0.00)$ & $3(0.70)$ \\
\hline Urban & $83(40.50)$ & $132(64.40)$ & $215(52.40)$ & Yes, previousily & $6(2.90)$ & $12(5.90)$ & $18(4.40)$ \\
\hline Educational status & & & & No never & $196(95.60)$ & $193(94.10)$ & $389(94.90)$ \\
\hline No education & $69(33.70)$ & $42(20.50)$ & $111(27.10)$ & \multicolumn{4}{|c|}{ Five or more serving of fruits per week } \\
\hline Primary & $71(34.60)$ & $66(32.20)$ & $137(33.40)$ & $>3$ days & $23(11.20)$ & $20(9.80)$ & $43(10.50)$ \\
\hline Secondary & $35(17.10)$ & $51(24.90)$ & $86(21.00)$ & 0-3 days & $182(88.80$ & $185(90.20)$ & $367(89.50)$ \\
\hline Tertiary & $30(14.60)$ & $46(22.40)$ & $76(18.50)$ & \multicolumn{4}{|c|}{ Compliance with general healthy eating plan } \\
\hline Occupational status & & & & 0-3 days (inadequate) & $158(77.10)$ & $149(72.70)$ & $307(74.90)$ \\
\hline Farmer & $107(52.20)$ & $73(35.60)$ & $180(43.90)$ & $>3$ days (adequate) & $47(22.90)$ & $56(27.30)$ & $103(25.10)$ \\
\hline Employee & $63(30.70)$ & $85(41.50)$ & $148(36.10)$ & \multicolumn{4}{|l|}{ Chew khat } \\
\hline Merchant & $9(4.40)$ & $16(7.80)$ & $25(6.10)$ & Yes, now & $85(41.50)$ & $72(35.10)$ & $157(38.30)$ \\
\hline Private & $7(3.40)$ & $6(2.90)$ & $13(3.20)$ & Yes, previously & $54(26.30)$ & $75(36.60)$ & $129(31.50)$ \\
\hline Housewife & $8(3.90)$ & $16(7.80)$ & $24(5.90)$ & No & $66(32.20)$ & $58(28.30)$ & $124(30.20)$ \\
\hline Others & $11(5.40)$ & $9(4.40)$ & $20(4.90)$ & \multicolumn{4}{|l|}{ Alcohol consumption } \\
\hline Income & & & & Yes & $27(13.20)$ & $39(19.00)$ & 66 (16.10) \\
\hline$<1500$ & $104(50.70)$ & $114(55.60)$ & $218(53.20)$ & No & $178(86.80)$ & $166(81.00)$ & $344(83.90)$ \\
\hline
\end{tabular}

Table 1 Socio-demographic characteristics of adult patients with type 2 diabetes mellitus on follow up at the diabetic clinic of Jimma University medical center, south-west Ethiopia, April 01-June 30, 2017 (Continued)

${ }^{a}$ Catholic and wake data, kambata, ${ }^{\mathrm{b}}$ walayita, Tigre and Silte, ${ }^{\mathrm{c}}$ Has not

Table 2 Diabetes self-care activities of adult patients with type

elf-monitoring blood glucose 
Table 3 Biochemical parameters and clinical characteristics of adult patients with type 2 diabetes mellitus on follow up at the diabetic clinic of Jimma University medical center, south-west Ethiopia, April 01-June 30, 2017

\begin{tabular}{|c|c|c|c|}
\hline Variables & Cases, N (\%) & Controls, N (\%) & Total, N (\%) \\
\hline \multicolumn{4}{|l|}{ Total cholesterol } \\
\hline$<200 \mathrm{mg} / \mathrm{dL}$ & $45(58.40)$ & $65(81.30)$ & 110)70.10) \\
\hline$\geq 200 \mathrm{mg} / \mathrm{dL}$ & $32(41.60)$ & $15(18.80)$ & $47(29.90)$ \\
\hline \multicolumn{4}{|l|}{ Triglyceride } \\
\hline$<150$ & $43(58.10)$ & $49(64.50)$ & $92(61.30)$ \\
\hline$\geq 150$ & $31(41.90)$ & $27(35.50)$ & $58(38.70)$ \\
\hline \multicolumn{4}{|l|}{ HDL } \\
\hline $\mathrm{M}: \geq 40 \mathrm{mg} / \mathrm{Dl}, \mathrm{F}: \geq 50 \mathrm{mg} / \mathrm{dL}$ & $44(60.30)$ & $42(55.30)$ & $86(57.70)$ \\
\hline $\mathrm{M}:<40 \mathrm{mg} / \mathrm{dL}, \mathrm{F}:<50 \mathrm{mg} / \mathrm{dL}$ & $29(39.70)$ & $34(44.70)$ & $63(42.30)$ \\
\hline \multicolumn{4}{|l|}{ LDL } \\
\hline$<100 \mathrm{mg} / \mathrm{dL}$ & $53(68.80)$ & $60(76.90)$ & $113(72.90)$ \\
\hline$\geq 100 \mathrm{mg} / \mathrm{dL}$ & $24(31.20)$ & $18(23.10)$ & $42(27.10)$ \\
\hline \multicolumn{4}{|l|}{ BMI } \\
\hline$<25$ & $131(63.90)$ & $129(62.90)$ & $260(63.40)$ \\
\hline $25-29.99$ & $56(27.30)$ & $60(29.30)$ & $116(28.30)$ \\
\hline$\geq 30$ & $18(8.80)$ & $16(7.80)$ & $34(8.30)$ \\
\hline \multicolumn{4}{|l|}{ Waist to hip ratio } \\
\hline $\mathrm{M}:<0.9, \mathrm{~F}:<0.85$ & $20(9.80)$ & $64(31.20)$ & $84(20.50)$ \\
\hline $\mathrm{M}: \geq 0.9, \mathrm{~F}: \geq 0.85$ & $185(90.20)$ & $141(68.80)$ & $326(79.50)$ \\
\hline \multicolumn{4}{|l|}{ Duration } \\
\hline$\leq 7$ years & $98(47.80)$ & $141(68.80)$ & $239(58.30)$ \\
\hline$>7$ years & $107(52.20)$ & $64(31.20)$ & $171(41.70)$ \\
\hline \multicolumn{4}{|l|}{ Types of antidiabetes medication } \\
\hline Glibenclimide alone & $4(2.00)$ & $3(1.50)$ & $7(1.71)$ \\
\hline Metformin+Glibenclimide & $74(36.10)$ & $49(23.90)$ & $123(30.00)$ \\
\hline Insulin alone & $65(31.70)$ & $64(31.20)$ & $129(31.46)$ \\
\hline Metformin + Insulin & $33(16.10)$ & $28(13.70)$ & $61(14.88)$ \\
\hline Metformin alone & $29(14.10)$ & $61(29.80)$ & $90(21.95)$ \\
\hline \multicolumn{4}{|l|}{ Polypharmacy } \\
\hline Yes & $49(23.90)$ & $21(10.20)$ & $70(17.10)$ \\
\hline No & $156(76.10)$ & $184(89.80)$ & $340(82.90)$ \\
\hline
\end{tabular}

\section{Predictors of poor glycemic control}

In bivariate logistic regression, marital status, educational level, place of residence, self-monitoring blood glucose, physical activities, comorbidity, duration since diagnoses of diabetes, adherence to antidiabetic medication during the week preceding the study, polypharmacy, types of antidiabetic medication, WHR and total cholesterol level were found to be associated with poor glycemic control and entered into multivariate logistic analysis. In multivariate logistic analysis, self-monitoring of blood sugar, duration since diagnosis of diabetes, physical activity, types of diabetes medication, comorbidities, total cholesterol level and WHR were found to be significantly associated with poor blood sugar control as depicted in Table 4.

Participants who had comorbidity/ies were 2.56 times more likely to have poor blood glucose control compared to those who had no comorbidity/ies $(\mathrm{AOR}=2.56,95 \% \mathrm{CI}=1.10-5.96)$. Respondents who were not self-monitoring their blood glucose were 3.44 times more likely to have poor glycemic control as compared to those who were monitoring their blood glucose level $(\mathrm{AOR}=3.44,95 \% \mathrm{CI}=1.33-8.94)$. Respondents who had total cholesterol of $\geq 200 \mathrm{mg} / \mathrm{dl}$ were 3.62 times more likely to have poorly controlled blood glucose compared to those who had 
Table 4 Bivariate and multivariate logistic regression of determinants of poor glycemic control among adult patients with type 2 diabetes mellitus in Jimma University Medical Center, April 01-June 30, 2017

\begin{tabular}{|c|c|c|c|c|}
\hline Variables & Cases & Control & Crude OR & Adjusted OR \\
\hline \multicolumn{5}{|l|}{ Educational status } \\
\hline No education & 69 (33.70) & $42(20.50)$ & $2.52(1.38-4.58)$ & $2.78(0.54-14.41)$ \\
\hline Primary & $71(34.60)$ & $66(32.20)$ & $1.65(0.93-2.91)$ & $1.33(0.36-4.94)$ \\
\hline Secondary & $35(17.10)$ & $51(24.90)$ & $1.05(0.56-1.97)$ & $0.72(0.18-2.80)$ \\
\hline Tertiary & $30(14.60)$ & $46(22.40)$ & 1 & 1 \\
\hline \multicolumn{5}{|l|}{ Place of residence } \\
\hline Rural & $122(59.50)$ & $73(35.60)$ & $2.66(1.78-3.96)$ & $0.66(0.24-1.85)$ \\
\hline Urban & $83(40.50)$ & $132(64.40)$ & 1 & 1 \\
\hline \multicolumn{5}{|l|}{ Comorbidity } \\
\hline Yes & $138(67.30)$ & $116(56.60)$ & $1.58(1.06-2.36)$ & • $2.56(1.10-5.96) *$ \\
\hline No & $67(32.70)$ & $89(43.40)$ & 1 & 1 \\
\hline \multicolumn{5}{|l|}{ Self-monitoring Blood Glucose } \\
\hline No & $164(80.00)$ & $144(70.20)$ & $1.69(1.07-2.67)$ & $3.44(1.33-8.94)^{*}$ \\
\hline Yes & $41(20.00)$ & $61(29.80)$ & 1 & 1 \\
\hline \multicolumn{5}{|l|}{ Total cholesterol } \\
\hline$\geq 200 \mathrm{mg} / \mathrm{dL}$ & $32(41.60)$ & $15(18.80)$ & $3.08(1.50-6.34)$ & $3.62(1.46-8.97)^{*}$ \\
\hline$<200 \mathrm{mg} / \mathrm{dL}$ & $45(58.40)$ & $65(81.30)$ & 1 & 1 \\
\hline \multicolumn{5}{|c|}{ Adherence to antidiabetic medication } \\
\hline No & $56(27.30)$ & $33(16.10)$ & $1.96(1.21-3.17)$ & $0.67(0.26-1.69)$ \\
\hline Yes & $149(72.70)$ & $172(83.90)$ & 1 & 1 \\
\hline \multicolumn{5}{|l|}{ Duration of diabetes } \\
\hline$>7$ years & $107(52.20)$ & $64(31.20)$ & $2.40(1.61-3.60)$ & $3.08(1.33-7.16) *$ \\
\hline$\leq 7$ years & $98(47.80)$ & $141(68.80)$ & 1 & 1 \\
\hline \multicolumn{5}{|l|}{ Physical activity } \\
\hline 0-3 days (inadequate) & $161(78.50)$ & $113(55.10)$ & $2.98(1.93-4.60)$ & $4.79(1.70-13.53) *$ \\
\hline > 3 days(adequate) & $44(21.50)$ & $92(44.90)$ & 1 & 1 \\
\hline \multicolumn{5}{|l|}{ Polypharmacy } \\
\hline Yes & $49(23.90)$ & $21(10.20)$ & $2.75(1.58-4.79)$ & $1.41(0.37-5.41)$ \\
\hline No & $156(76.10)$ & $184(89.80)$ & 1 & 1 \\
\hline \multicolumn{5}{|l|}{ Marital status } \\
\hline Single/divorced/widowed & $54(26.30)$ & $32(15.60)$ & $1.93(1.19-3.15)$ & $1.80(0.68-4.72)$ \\
\hline Married & $151(73.70)$ & $173(84.40)$ & 1 & 1 \\
\hline \multicolumn{5}{|l|}{ Waist to hip ratio } \\
\hline $\mathrm{M}: \geq 0.9, \mathrm{~F}: \geq 0.85$ & $185(90.20)$ & $141(68.80)$ & $4.20(2.43-7.26)$ & $3.52(1.23-10.11) *$ \\
\hline $\mathrm{M}:<0.9, \mathrm{~F}:<0.85$ & $20(9.80)$ & $64(31.20)$ & 1 & 1 \\
\hline \multicolumn{5}{|c|}{ Types of antidiabetes medication } \\
\hline Glibenclimide alone & $4(2.00)$ & $3(1.50)$ & $2.80(0.59-13.36)$ & $3.57(0.18-68.66)$ \\
\hline Metformin+Glibenclimide & $74(36.10)$ & $49(23.90)$ & $3.18(1.80-5.62)$ & $9.22(2.90-29.35)^{*}$ \\
\hline Insulin alone & $65(31.70)$ & $64(31.20)$ & $2.14(1.22-3.74)$ & $4.48(1.52-13.16)^{*}$ \\
\hline Metformin + Insulin & $33(16.10)$ & $28(13.70)$ & $2.48(1.27-4.84)$ & $3.73(0.87-16.05)$ \\
\hline Metformin alone & $29(14.10)$ & $61(29.80)$ & 1 & 1 \\
\hline
\end{tabular}


total cholesterol of less than $200 \mathrm{mg} / \mathrm{dl}(\mathrm{AOR}=3.62$, $95 \% \mathrm{CI}=1.46-8.97$ ). Respondents who were diagnosed with diabetes more than seven years ago were 3.08 times more likely to have poorly controlled blood glucose than respondents diagnosed with diabetes less than or equal to seven years ago $(\mathrm{AOR}=3.08,95 \% \mathrm{CI}=1.33-7.16)$.

Respondents who do $30 \mathrm{~min}$ physical activity for 1 to 6 days were 4.79 times more likely to have poorly controlled blood glucose compared to those who do 30 min physical activity daily (AOR $=4.79,95 \% \mathrm{CI}=1.70-13.53$ ).

Participants who had a WHR of " $\geq 0.9$ " for male or $\geq$ 0.85 " for female were 3.52 more likely to have poorly controlled blood glucose level as compared to participants who have a WHR of " $<0.9$ " for male or " $<0.85$ " for female (AOR $=3.52,95 \% \mathrm{CI}=1.23-10.11)$.

Those diabetes patients who were on the combination of metformin and glibenclamide were 9.22 times more likely to have poorly controlled blood glucose compared to those patients who were on metformin alone $(\mathrm{AOR}=9.22$, $95 \% \mathrm{CI}=2.90-29.35)$. Similarly, patients who were on insulin alone were 4.48 times more likely to be poorly controlled than patients who were on metformin alone $(\mathrm{AOR}=4.48,95 \% \mathrm{CI}=1.52-13.16)$.

\section{Discussion}

Glycemic control is the major therapeutic goal for prevention of organ damage and related complication of diabetes [30]. The American Diabetes Association recommends an HbA1c level of below $7 \%$ as a target for optimal blood glucose control and further recommended adequate glycemic control with pre-prandial capillary plasma glucose $80-130 \mathrm{mg} / \mathrm{dl}$ [25].

This study showed that high WHR, total cholesterol of $200 \mathrm{mg} / \mathrm{dl}$ or more, duration of diabetes of 7 years or more, physical activity of less than four days, not self-monitoring blood glucose, types of antidiabetic medication and presence of comorbidity were significantly associated with poorer glycemic control.

The finding from this study suggests that patients with the high WHR had higher odds of having poorly controlled blood glucose. The study conducted in Malaysia also determined that an increasing central obesity was significantly associated with poor HbA1c control [31]. Another study conducted at McGill University-affiliated outpatient clinics were also pointed that for each standard deviation (0.08 unit) increase in WHR there was an approximately $0.35 \%$ higher HbA1C [24].

In addition to this, research conducted in Japan, North America and Iran also indicated that abdominal obesity is an important factor in the diabetes control where they have revealed the association between glycemic control and waist circumference [32-34]. Obesity increases the secretion of Non Esterified Fatty Acids (NEFAs) from adipose tissue. NEFAs is associated with insulin resistance $[35,36]$. This might be a reason for poor glycemic control in obese patients with diabetes mellitus. Patients with total cholesterol of $200 \mathrm{mg} / \mathrm{dl}$ or more were more likely to have poor glycemic control compared to patients with the total cholesterol of less than $200 \mathrm{mg} / \mathrm{dl}$.

A study conducted in San Diego has also demonstrated that patients with total cholesterol level $\geq 200$ $\mathrm{mg} / \mathrm{dl}$ had a higher mean A1C $(8.0 \%)$ than those with lower total cholesterol level, A1C 7.5\% [37]. Similarly, studies conducted in Ethiopia, at Ambo hospital and Tikur Anbessa Specialized Hospital, revealed that patients who had hyperlipidemia were at a more risk of developing poor glycemic control than patients with no comorbidities [19, 21]. This could be because of elevated triglyceride as part of total cholesterol, which results in increasing free fatty acid, which intern related to inflammation and eventually result in insulin resistance or impaired cell function [38].

Duration since diagnoses of diabetes was also another predictor of poor glycemic control.

Patients who had diabetes for the longer duration (greater than 7 years) were more likely to have poor glycemic control. A study conducted in Hawaii (2006) also indicated that patients who had diabetes for more than 10 years were more likely to have poor glycemic control than those who had diabetes for 3 years [39]. In line with these results, a study done by Akour et al. (2011) revealed that patients who were diagnosed with diabetes more than ten years ago were more likely to have poor glycemic control compared to those with duration of less than or equal to 10 years [40]. This is may be due to progressive impairment of insulin secretion with time by $ß$ - cell and increase in insulin resistance and a sudden decrease in insulin secretion [41].

In contradiction to these findings, the study done by Nichols et al. (2000) indicated that the duration of the diagnosis of the disease is not a significant factor for glycaemic control, rather there is a poorer metabolic control among the younger age groups [23].

Physical activity was also another predictor of poor glycemic control. A patient envolved in physical activity only for less than three days were more likely to have poor glycemic control compared to those doing the regular physical activity for more than three days. This is in line with the study done in Jordan and Thailand [30, 42]. This might be because of increasing glucose uptake by the working muscle than a muscle at rest, because physical activity increases the blood flow to the muscle and eventually increases the number of insulin receptors, which finally result in increasing insulin sensitivity $[43,44]$.

In this study respondents who were not self monitored their blood glucose had higher odds of having poorly controlled blood glucose compared to those who self 
monitored their blood glucose. A study conducted in Jordan also showed that patients who were less adherent to SMBG had poor glycemic control [30]. Like wise another study conducted in Northern California showed that adherence to SMBG was significantly associated with the lower HbA1c level [45]. Moreover, a study conducted in Mekelle city indicated that patient who adherent to SMBG had good glycemic control [18].

A patient who didn't self-monitor their blood glucose may not consult health care providers frequently as patients who self-monitor their blood glucose. This could contribute to poor glycemic control in patients who didn't self-monitor their blood glucose. In addition to this patients who didn't self-monitor their blood glucose may not adjust their antidiabetic medication and modify their eating plan, though the study done in western Kenya reported that there was no any association between adherence to SMBG and glycemic control. This controversy might be related to small sample size (only 164 participants) were included in the study mentioned above. In addition to this, the patients enrolled were aslo patient with poorly controlled HbA1c [46].

Types of antidiabetic medication were associated with glycemic control. Patients on insulin were more likely to have poorly controlled blood glucose than those on metformin alone. This was in line with the study done in India, which showed that patients on insulin alone had higher odds of poor glycemic control [47].

Similarly, a study conducted by Egede et al. found that the odds of having uncontrolled HbA1c were higher in individuals using insulin only compared to patients taking oral hypoglycemic medication only [48]. This might be due to patients who were prescribed with insulin could have more severe diabetes and diabetes of a longer duration.This was largely contributed by the fact that -cell function worsened as the duration of diabetes increased from the time of diagnosis through follow up [49]. Similarly, patients on metformin plus glibenclamide have a higher probability of poor glycemic control compared to a patient on metformin alone. This could be due to drug therapy problem. For instance the study done in Indonesia showed that the number of medications signifcantly predicted the number of drug related problem [50].This drug related problem in turn affect blood glucose control. But, this study didn't address factors related to drug therapy problems.

Patients who have one or more comorbidity have higher odds of having poor glycemic control. The study conducted in India revealed that the presence of diseases such as coronary heart disease, neuropathy, retinopathy, renal failure and neurological disorders was associated with poor control of diabetes [51]. Similarly, a study done in Mekelle town northern, found that patient who had hypertension as one part of comorbidity were more likely to be poorly controlled [18]. The reason for comorbidity as a predictor of poor glycemic control might be due to poor adherence of the patients to the medication because of additional medication for the comorbidity might be increasing the pill burden to the patient.

\section{Strength and limitation of the study The strength of the study}

Since this study was case-control its strength of identifying the predictors of poor glycemic is better than cross-sectional study done in Ethiopia previously.

\# The sample size of this study was larger than many studies done in Ethiopia previously.

\section{Limitation of the study}

As some parts of the questionnaire depended on the memory of respondents may have resulted in recall bias. Patients with newly diagnosed type 2 diabetes were not included. It was done only among type 2 diabetes patients who were on follow up at outpatient clinic which may not be representative of the overall type 2 diabetes population. HbA1c was not used due to unavailability in the hospital.

\section{Conclusion}

Lack of self-monitoring blood glucose, the presence of comorbidity, longer duration of diabetes mellitus, physical activity of 3 days or less, a total cholesterol level of 200 $\mathrm{mg} / \mathrm{dl}$ or more, high waist to hip ratio, being on insulin or a combination of metformin with glibenclamide were the independent predictors of poor glycemic control. The health care provider have to encourage the patients during every visit to do $30 \mathrm{~min}$ of physical activity.

\section{Abbreviations \\ AOR: Adjusted Odds Ratio; BSc: Bachelor of Science; JUMC: Jimma University Medical Center

\begin{abstract}
Acknowledgements
Authors are very grateful for the study participants, data collectors and supervisors.
\end{abstract} \\ Authors' contributions \\ YM involved in conceiving the idea, study design, data analysis and interpretation and managing the overall progress of the study. FB involved in study design, data analysis and writing up of the manuscript. Both TN and AZ equally contributed in study design, data analysis and in revising the manuscript. The final manuscript was read and approved by all the authtors.}

Funding

No funding was received to conduct this study.

Availability of data and materials

The data set is available with authors and can be obtained from the corresponding author up on reasonable request. 


\section{Ethics approval and consent to participate}

This study was approved by research ethical review board of Jimma University. Patients were requested for written informed consent. The anonymity of data was kept at all stage of data processing.

\section{Consent for publication}

Not applicable.

\section{Competing interests}

All authors declared that there is no competing interest.

\section{Author details}

'Department of Pharmacy, College of medicine and health science, Mizan Tepi University, Mizan Teferi, Ethiopia. ${ }^{2}$ Department of Pharmacy, Jimma University Institute of Health Science, Jimma, Ethiopia. ${ }^{3}$ Department of Public Health, College of medicine and health science, Mizan Tepi University, Mizan Teferi, Ethiopia. ${ }^{4}$ Department of Pharmacy, College of medicine and health science, Mizan Tepi University, Mizan Teferi, Ethiopia.

Received: 19 November 2018 Accepted: 20 August 2019 Published online: 29 August 2019

\section{References}

1. International Diabetes Federation. Diabetes and cardiovascular disease. Brussels: International Diabetes Federation; 2016.

2. Fowler MJ. Microvascular and Macrovascular Complications of Diabetes. Clinical Diabetes. 2008;26:77-82.

3. Turner R, Holman R, Cull C. Intensive blood-glucose control with sulphonylureas or insulin compared with conventional treatment and risk of complications in patients with type 2 diabetes. Lancet. 1998;352:837-53.

4. Diabetes complication control Trial group. The effect of intensive treatment of diabetes on the development and progression of long-term complications in insulin-dependent diabetes mellitus. The Diabetes Control and Complications Trial Research Group. N Engl J Med. 1993;329:977-86.

5. Kelly N, Bazzano A, Fonseca A, Thethi K, Reynolds K, Jiang H. Glucose Control and Cardiovascular Disease in Type-2 Diabetes: A meta-analysis. Ann Intern Med. 2010;152(1):63-4

6. Mohan V, Seedat YK, Pradeepa R. The Rising Burden of Diabetes and Hypertension inSoutheast Asian and African Regions: Need for effective strategies for Prevention and Control in Primary Health Care Settings. Int J Hypertens. 2013;2013:409083.

7. Rathmann W, Giani G. Global prevalence of diabetes: estimates for the year 2000 and projections for 2030. Diabetes Care. 2004;27(10):2568-9.

8. Rahelić D. OF IDF DIABETES ATLAS--CALL FOR IMMEDIATE ACTION. Liječnički vjesnik. 2016;138(1-2):57.

9. Aspray TJ, Mugusi F, Rashid S, Whiting D, Edwards R, Alberti KG, et al. Rura and urban differences in diabetes prevalence in Tanzania: the role of obesity, physical inactivity, and urban living. Trans R Soc Trop Med Hyg. 2000;94(6):637-44

10. Edwards R, Unwin N, Mugusi F, Whiting D, Rashid S, Kissima J, et al. Hypertension prevalence and care in an urban and rural area of Tanzania. J Hypertens. 2000;18(2):145-52.

11. Misganaw A, Mariam DH, Araya T. The double mortality burden among adults in Addis Ababa, Ethiopia, 2006-2009. Prev Chronic Dis. 2012;9:E84.

12. Eckel RH, Kahn SE, Ferrannini E, Goldfine AB, Nathan DM, Schwartz MW, et al. Obesity and type 2 diabetes: what can be unified and what needs to be individualized? J Clin Endocrinol Metab. 2011;96(6):1654-63.

13. Hardy OT, Czech MP, Corvera S. What causes the insulin resistance underlying obesity? Curr Opin Endocrinol Diabetes Obes. 2012;19(2):81-7.

14. Zoungas S, Chalmers J, Ninomiya T, Li Q, Cooper M, Colagiuri S, et al. Association of $\mathrm{HbA1c}$ levels with vascular complications and death in patients with type 2 diabetes: evidence of glycaemic thresholds. Diabetologia. 2012;55:636-43.

15. Davies $M$. The reality of glycaemic control in insulin-treated diabetes: defining the clinical challenges. Int J Obes. 2004;28(S2):S14.

16. Chan JC, Gagliardino JJ, Baik SH, Chantelot J-M, Ferreira SR, Hancu N, et al. Multifaceted determinants for achieving glycemic control. Diabetes Care. 2009;32(2):227-33.

17. Ahmad NS, Islahudin F, Paraidathathu T. Factors associated with good glycemic control among patients with type 2 diabetes mellitus. J Diabetes Invest. 2014;5:563-9.
18. Eticha T, AbrahaleyMulu HG, GetuKahsay DA, Rajeshwar Y. Factors associated with poor glycemic control in type 2 diabetic patients investigated at Ayder referral hospital, Mekelle, Ethiopia ljppr. Human. 2016;6(3):160-71.

19. Mullugeta Y, Chawla R, Kebede T, Worku Y. Dyslipidemia associated with a poor glycemic control in type 2 diabetes mellitus and the protective effect of metformin supplementation. Indian J Clin Biochem. 2012;27(4):363-9.

20. Kassahun T, Eshetie T, Gesesew H. Factors associated with glycemic control among adult patients with type 2 diabetes mellitus: a cross-sectional survey in Ethiopia. BMC research notes. 2016;9(1):78.

21. Woldu M, Wami C, Lenjisa J, Tegegne G, Tesafye G, Dinsa H. Factors associated with poor glycemic control among patients with type 2 diabetes mellitus in ambo hospital. Ambo; Ethiopia Endocrinol Metab Synd. 2014; 3(143):2161-1017.1000143.

22. Toobert DJ, Hampson SE, Glasgow RE. The summary of diabetes self-care activities measure: results from 7 studies and a revised scale. Diabetes Care. 2000;23(7):943-50

23. Nichols GA, Hillier TA, Javor K, Brown JB. Predictors of glycemic control in insulin-using adults with type 2 diabetes. Diabetes Care. 2000;23(3):273-7.

24. Manjoo P, Joseph L, Dasgupta K. Abdominal adiposity and daily step counts as determinants of glycemic control in a cohort of patients with type 2 diabetes mellitus. Nutrition \& diabetes. 2012;2(1):e25.

25. Ivanov TD, Ivanova M. American Diabetes Association. Standards of medical Care in Diabetes-2017. Kidneys. 2017;6(1):47-63.

26. Bjerrum L, Rosholm JU, Hallas J, Kragstrup J. Methods for estimating the occurrence of polypharmacy by means of a prescription database. Eur J Clin Pharmacol. 1997;53(1):7-11.

27. NHLBI Obesity Education Initiative. The practical guide: Identification, evaluation, and treatment of overweight and obesity in adults. National Institutes of Health (NIH Publication Number 00-4084), 2000.

28. WHO. Definition, diagnosis, and classification of diabetes mellitus and its complications: Report of a WHO consultation. Geneva: World Health Organization (WHO); 1999.

29. WHO STEP wise approach to surveillance (STEPS). Geneva, World Health Organization (WHO), 2008.

30. Khattab M, Khader YS, Al-Khawaldeh A, Ajlouni K. Factors associated with poor glycemic control among patients with type 2 diabetes. J Diabetes Complicat. 2010;24(2):84-9.

31. Al-Zurfi BMN, Aziz AA, Abdullah MR, Noor N. Waist-height ratio compared to body mass index and waist circumference in relation to glycemic control in Malay type 2 diabetes mellitus patients, hospital university sains Malaysia. Int J Collab Res Intern Med Public Health (IJCRIMPH). 2012;4:406.

32. Yoshida D, Toyomura K, Fukumoto J, Ueda N, Ohnaka K, Adachi M, et al. Waist circumference, body mass index and glycated hemoglobin in Japanese men and women. Diabetes Metab Syndr Clin Res Rev. 2009:3(1):7-11.

33. Okosun IS, Dever G. Abdominal obesity and ethnic differences in diabetes awareness, treatment, and glycemic control. Obesity. 2002;10(12):1241-50.

34. Ghazanfari Z, Niknami S, Ghofranipour F, Larijani B, Agha-Alinejad H, Montazeri A. Determinants of glycemic control in female diabetic patients: a study from Iran. Lipids Health Dis. 2010;9(1):83.

35. Kahn SE, Hull RL, Utzschneider KM. Mechanisms linking obesity to insulin resistance and type 2 diabetes. Nature. 2006;444(7121):840-6.

36. Elic K, Luzio SD, Dunseath G, Colding-Jorgsensen M, Owens DR. Cross-sectional analysis of NEFA levels following a standard mixed meal in a population of persons with newly diagnosed type 2 diabetes mellitus across a spectrum of glycemic control [abstract]. American Diabetes Association: Alexandria; 2007.

37. Benoit SR, Fleming R, Philis-Tsimikas A, Ji M. Predictors of glycemic control among patients with type 2 diabetes: a longitudinal study. BMC Public Health. 2005;5(1):36

38. Parhofer KG. The interaction between glucose and lipid metabolism: more than diabetic dyslipidemia. Diabetes Metab J. 2015;39:353-62.

39. Juarez DT, Sentell T, Tokumaru S, Goo R, Davis JW, Mau MM. Peer reviewed: factors associated with poor glycemic control or wide glycemic variability among diabetes patients in Hawaii, 2006-2009. Prev Chronic Dis. 2012;9: 120065

40. Al-Akour N, Khader Y, Alaoui A. Glycemic control and its determinants among patients with type 2 diabetes mellitus attending a teaching hospital. Jiabetes Metab. 2011;2:129.

41. Group UPDS. Intensive blood-glucose control with sulphonylureas or insulin compared with conventional treatment and risk of complications in patients with type 2 diabetes (UKPDS 33). Lancet. 1998;352(9131):837-53. 
42. Howteerakul N, Suwannapong N, Rittichu C, Rawdaree P. Adherence to the regimens and glycemic control of patients with type 2 diabetes attending a tertiary hospital clinic. Asia Pacific J Public Health. 2007;19(1):43-9.

43. Shivananda $\mathrm{N}$, Arun $\mathrm{M}$, Manjunath $\mathrm{H}$. Influence of aerobic treadmill exercise on blood glucose homeostasis in noninsulin-dependent diabetes mellitus patients. Indian J Clin Biochem. 2005;20(1):47-51.

44. Wahren J, Felig P. During leg exercises. J Clin Invest. 1971;50:2715-25.

45. Karter AJ, Ackerson LM, Darbinian JA, D'Agostino RB, Ferrara A, Liu J, et al. Self-monitoring of blood glucose levels and glycemic control: the northern California Kaiser Permanente diabetes registry*. Am J Med. 2001;111(1):1-9.

46. Charity KW, Kumar AM, Hinderaker SG, Chinnakali P, Pastakia SD, Kamano J. Do diabetes mellitus patients adhere to self-monitoring of blood glucose (SMBG) and is this associated with glycemic control? Experiences from an SMBG program in western Kenya. Diabetes Res Clin Pract. 2016;112:37-43.

47. Unnikrishnan R, Anjana RM, Deepa M, Pradeepa R, Joshi SR, Bhansali A, et al. Glycemic control among individuals with self-reported diabetes in India—-the ICMR-INDIAB study. Diabetes Technol Ther. 2014;16(9):596-603.

48. Egede LE, Gebregziabher M, Hunt KJ, Axon RN, Echols C, Gilbert GE, et al. Regional, geographic, and racial/ethnic variation in glycemic control in a national sample of veterans with diabetes. Diabetes Care. 2011;34(4):938-43.

49. Group UPDS. UK prospective diabetes study 16 : an ovenview of 6 years' therapy of type II diabetes: a progressive disease. Diabetes. 1995;44(11):1249-58.

50. Zazuli Z, Rohaya A, Adnyana IK. Drug-related problems in type 2 diabetic patients with hypertension: a prospective study. J Basic Clin Pharma. 2017;8:251-4.

51. Sanal T, Nair N, Adhikari P. Factors associated with poor control of type 2 diabetes mellitus: a systematic review and meta-analysis. J Diabetology. 2011;3(1):1-10

\section{Publisher's Note}

Springer Nature remains neutral with regard to jurisdictional claims in published maps and institutional affiliations.

Ready to submit your research? Choose BMC and benefit from:

- fast, convenient online submission

- thorough peer review by experienced researchers in your field

- rapid publication on acceptance

- support for research data, including large and complex data types

- gold Open Access which fosters wider collaboration and increased citations

- maximum visibility for your research: over $100 \mathrm{M}$ website views per year

At $\mathrm{BMC}$, research is always in progress.

Learn more biomedcentral.com/submissions 